J O U R N A L

$\mathrm{O} F \bullet \mathrm{B} A \mathrm{~L} T \mathrm{I} C$

$S$ C I E N C E

EDUCATION

\section{ISSN 1648-3898 /Print/ ISSN 2538-7138}

\title{
EVALUATION DF INTERACTIVE GAME-BASED LEARNING IN PHYSICS DOMAIN
}

Abstract. In recent years, game-based learning has attracted much attention in education; however, the effectiveness of game-based learning is still not solidly confirmed. In the present research, a gamebased learning in the physics domain with

guides provided direct and immediate feedback. The research was conducted among three different groups: the traditional group, the educational video group, and the game-based learning group. The result showed that the game-based learning group performed the best among the three groups, followed by the educational

video group, and the traditional group performed the worst. Students in the gamebased learning group were enrolled into an interview to study which types of guides enhanced students' game-based learning.

From the interview, the prompts and the

interactive characteristic of the gamebased learning environment took the first two places. In addition, students benefited from the features of game-based learning including task requirements for execution, the tip prompt function, the feedback mechanism, and the story settings. Therefore, it is necessary to integrate applicable guides into the design of game-based learning according to students' perspectives for providing engaging learning experience.

Keywords: game-based learning, knowledge acquisition, learning guidelines, physics education.

Hui Zeng, Shao-Na Zhou South China Normal University, China Gui-Rong Hong Shenzhen Senior High School Group, China

Qiu-ye Li

South China Normal University, China

Shao-Qiu Xu

Guangdong University of Technology, China

\section{Hui Zeng, Shao-Na Zhou, Gui-Rong Hong, Qiu-ye Li, Shao-Qiu Xu}

\section{Introduction}

In recent years, with the wide spread of electronic devices such as computers and mobile phones, more and more attention has been drawn to game-based learning in the pedagogical process. For game-based learning, it is designed integrating learning contents and digital games to help learners obtain certain subjects through applying learning contents to the real world (Chang, et al., 2017; Prensky, 2001). Game-based learning has demonstrated great potential as a powerful learning tool for the pedagogical process. Raybourn and Bos (2005) described that the opportunities of experiencing abstract concepts and augmenting students' learning could be provided in a game-based learning environment. Prensky (2001) pointed out that game-based learning characteristics including rules, interactivity, goals, feedback, and challenges are the key factors to consider in designing engaging gaming experience.

Even though game-based learning has attracted much attention in education field, there is still a lack of consensus on their effectiveness. Some studies find significant relationships between game-based learning and science content, while some studies assert that game-based learning has insignificant effects on science learning. On the one hand, the positive role of game-based learning has been supported by a number of researchers (e.g.,Tüzün et al., 2009). Game-based learning has been promoted as an effective method in enhancing students' interest and improving learning efficiency on science education (Cheng et al., 2015; Mayo, 2007; Quintana et al., 2004). Students have demonstrated improvement on science learning after playing in a collaborative mode of game-based learning (Chen et al., 2015). D'Angelo (2010) has indicated that game-based learning could help students connect the game to specific science content and bridge the gap between the knowledge structures learned at school and student learning in game environments. Cheng et al. (2015) has found that players could learn from game-based learning and the game immersion experience could lead to better gaming performance. 
On the other hand, some researchers have argued that the disconnection between game-based learning and science content could bring about insignificant outcomes. In game-based learning, there may be a lack of articulation and reflection on the target content knowledge for learning purposes (van der Meij et al., 2011). Wu et al. (2012) has criticized that most designers rarely stated the theoretical basis of game-based learning, while they specifically emphasized the design processes and the technological applications. Without focusing on theoretical basis of learning, the effectiveness of game-based learning would be greatly limited. Therefore, theoretical basis of learning and guidelines in game-based learning are vital factors to consider for encouraging students to reflect on the content knowledge and bridge the gap between game-based learning and science content (Young et al., 2012).

\section{Literature Review}

\section{Multimedia learning and game-based learning}

With the help of digital technology, multimedia enable educators to enrich students' learning experience including joyfulness, achievements, incentives, interest, and so on (Mayer, 2003). Multimedia learning environments are designed with various resources, such as texts, graphs, pictures, and animations. Mayer and Moreno (2003) proposed a cognitive theory of multimedia learning describing the cognitive process when students participate in multimedia learning. Based on the cognitive theory, appropriate designs of multimedia learning materials could lower cognitive load and enhance students' learning interests and motivations. While, insufficient or abundant implementation of multimedia learning materials could increase cognitive load, decrease students' interests, and result in inefficient learning achievements. Some other researchers (Lai \& Chang, 2011; Liu et al., 2009; Shepherd \& Martz, 2006; Sun \& Cheng, 2007) extended cognitive theory to media richness theory and explored the designs of multimedia learning materials. These studies pointed out that a better learning outcome and lower cognitive load could be achieved by effective presentations of multimedia information. Cognitive theory of multimedia learning and media richness theory have demonstrated the importance of the appropriateness in designing multimedia learning materials.

Compared with traditional multimedia learning, game-based learning has more interactive features including simulation, interactivity, and a sense of presence (Faiola et al., 2013; Schrader \& Bastiaens, 2012; Sitzmann, 2011). Simulation enables educators to bring the realistic phenomena into the game and guide students to bridge the gap between virtual games and real life (Sitzmann, 2011). Interactivity is the adequate response between games and players, which could bring about strong interest and efficient learning. A sense of presence allows students to participate and experience a virtual environment and immerse in the observation, exploration, and judgment (Faiola et al., 2013; Schrader \& Bastiaens, 2012).

Game-based learning can outperform traditional multimedia learning in the promotion of students' attitudes, behaviors and learning achievements. Gros (2007) pointed out that multimedia learning without interactive games tended to enhance text comprehension, while learning with interactive games tended to facilitate the complicated conceptual understanding. Ritterfeld et al. (2009) demonstrated that game-based learning achieved better in strengthening participants' existing conceptual knowledge than a pre-recorded video clip of game play. Papastergiou (2009) also found that students had less learning interest in a traditional learning environment than in a game-based environment. The vivid interactive experience of game-based learning could generate stronger learning motivation. Moreover, game-based learning is helpful to heighten students' attention and maintain longer concentration (Garris et al., 2002; Huang, et al., 2015; Papastergiou, 2009).

\section{Learning guidelines}

To improve the effectiveness of game-based learning in the pedagogical process, designers need to customize game-based learning with appropriate guidelines. Palinscar and Brown (1984) stated that learning guidelines are important instructional strategies that can help learners advance their learning abilities. Bruner (1985) believed that when the systematic learning guidelines matched students' mental models, new content knowledge could be more easily merged into existing knowledge structures. Achieving expected learning outcomes and providing joyfulness were considered as important objectives in the development of game-based learning. Becker (2007) suggested that students' perspectives and applicable instructions should be incorporated into the process of designing game-based learning for providing engaging learning experience. Jabbar and Felicia (2015) described that appropriate guidelines based on students' learning requirements should be included in game-based learning for helping students solve the problems and finish the learning tasks. Fisch (2005) pointed out that well-designed guidelines could refine learners' game-based learning strategies and enhance the learning outcomes. For example, 
self-explanation was incorporated into a game-based learning by Hsu and Tsai (2013) to advance students' acquisition of abstract concepts on light and shadow in primary school. Several researchers also suggested complementing game-based learning with external guides that bridged the gap between the achievement in the game and the instructional knowledge at school (Barzilai \& Blau, 2014; Charsky \& Mims, 2008; Quintana et al., 2004).

However, the design with different levels of guidance for game-based learning may result in diverse effects, so that the effectiveness of various learning guidelines remains controversial. Some researchers suggested that students should learn with direct instructional guidance on the procedures and concepts to reduce the cognitive load (e.g., Kirschner et al., 2006; Moreno, 2004). Moreno (2004) pointed out that novice students could reduce their cognitive load and learn better from guides of strongly guided instruction than from exploration. Kirschner et al. (2006) also found that specific guides were more effective than minimal guidance in assisting cognitive processing. Other researchers, however, argued that, from the perspective of constructive learning, students should be assisted with unguided or minimally guided instruction (e.g., Adams et al., 2009; Chang, 2016; Steffe \& Gale, 1995). Adams et al. (2009) explored the extent to which guides facilitated engaged learning in interactive simulations and reported that minimal guidance exerted optimum effects in physics simulations. Chang (2016) also found minimal guidance such as driving question approach to be beneficial to students' cognitive engagement.

Besides, it is unclear which types of guides should be provided to the students in game-based learning environments. According to previous research, the guide of reflection prompt, a type of prompts in game-based learning, has been found effective in knowledge integration (Davis \& Linn, 2000), math learning (Lee \& Chen, 2009), self-regulated learning competence (van den Boom et al., 2004), and problem solving (Kauffman et al., 2008). Specifically, two types of reflection prompts including knowledge prompt and application prompt, have been discussed in the existing literature. Knowledge prompt has been applied in some studies to enhance students' conceptual understanding of essential knowledge in game-based learning environment (e.g., Tsai et al., 2013), while application prompt has also been given to students to reflect not only on the conceptual understandings but also on knowledge application beyond the game contexts (Barzilai \& Blau, 2014).

\section{Research Focus}

Based on above literature review, it could be learned that game-based learning, which provides students an active learning environment to obtain knowledge and solve problems through game tasks, is a future trend for education (Hmelo-Silver et al., 2007). In the present research, game-based design was provided in physics domain with guides of both knowledge prompt and application prompt with direct and immediate feedback to improve student learning outcomes.

Besides, the timing of prompts in game-based learning, which has been also examined by researchers (Barzilai \& Blau, 2014; Tsai et al., 2013), was also considered in the present design. The previous studies suggested that it was important to prompt content knowledge before and within the game. However, the present research assumed that students could enhance their understanding in the game tasks without any preview materials or instructions. It is a well-known fact for young students, and it may also be observed for elder students. Therefore, the following research questions were proposed:

1. Do secondary school students acquire conceptual knowledge with guidelines in the game-based learning group, comparing to the educational video group and the traditional group?

2. Which types of guides enhance secondary school students' learning in game-based learning?

\section{Research Methodology}

\section{A Pilot Research of Student Learning Difficulties in Physics Domain}

In China, the sophisticated physical content knowledge of elastic force is normally taught in Year 10 of secondary school. According to the curriculum standards of the Ministry of Education (MOE) in China, students in Year 8 of secondary school (junior school) have been introduced the simple concept that elastic force is the force generated by an object due to elastic deformation, and taught how to measure the magnitude of a provided elastic force in simple phenomena. Before that, students may have seen some phenomena of deformation in daily life. While in Year 10, one of the important teaching objectives is to identify the existence of elastic force and to determine the direction of elastic force. Students need to understand that the conditions for generating an elastic force consist of both contact and elastic deformation, and the direction of elastic force is opposite to the direction of deformation. It is considered difficult as most contacts between objects are rigid, with no obviously tangible deformation. In accordance with this situation, elastic force was selected as the targeted content of the present design of game- 
based learning for secondary school students in Year 10. In order to understand the general teaching practice on elastic force, and to better organize and arrange the content knowledge for the design, a pilot interview was conducted with 64 teachers who taught physics in Year 10 of secondary school. Among these teachers, 24 of them were from urban areas and 40 of them were from towns and rural areas. The interview which aimed at providing authentic and reliable reference for the design of game-based learning, included the following three questions: 1) how was the effectiveness of teaching elastic force? 2) what were students' learning difficulties on elastic force? 3) what caused the difficulties in teaching elastic force?

In terms of the question "how was the effectiveness of teaching elastic force?", 75\% teachers considered that they were not satisfied with their instructional effect on elastic force, while $16.7 \%$ could not decide whether it was effective. Only a very small number of teachers ( $8.3 \%$ ) believed that they could well cope with the teaching on elastic force. For the question "what were students' learning difficulties on elastic force?", 59.4\% teachers raised the knowledge point that "elastic forces do not necessarily occur between bodies in contact" was the most difficult point for students to understand and the most error-prone; Following that, $57.8 \%$ of the teachers agreed that the principle "the direction of elastic force is expressed as perpendicular to the contact surface of two objects" also created comprehension difficulties for students. Another significant learning difficulty of "the direction of elastic force is opposite to the direction of deformation", accounted for $35.9 \%$.

For the question "what caused the difficulties in teaching elastic force?", most teachers pointed out that due to the invisibility of elastic force, experiment demonstrations were usually adopted for analyzing and explaining the result. Moreover, students were often taught to judge whether an object could remain in its original state when the object in contact with it was removed. This method was called presumptive judgment. $62.5 \%$ of those teachers, however, considered it difficult to explain with presumptive judgment, and $42.2 \%$ thought that the experiment to demonstrate "elastic forces do not necessarily occur between bodies in contact" was not sophisticated enough, and it was insufficient to express the original intention of teaching, both of which constituted difficulties for students to fully comprehend the content knowledge.

According to the interview, it was difficult for students to master the content knowledge of elastic force through traditional education. And two major difficulties in teaching and learning elastic force were the identification of existence and the judgment of direction of elastic force due to the invisibility with the traditional teaching method. Some inspirations were, therefore, obtained for designing the game-based learning of elastic force: first, to provide more intuitive and perceivable demonstration and to visualize the direction of elastic force with computer software, avoiding abstract and difficult theoretical analysis; then, to turn content knowledge learning into gamebased learning, making use of the high interactivity that would enable students to enjoy the process of knowledge construction in human-computer interaction.

\section{The Design of Game-based Learning on Learning Elastic Force}

The game-based learning which was developed with Adobe Flash CS6 included two modules. The first module (Trial 1) was designed to learn how to identify the existence of elastic force. While the second module (Trial 2) aimed at helping students determine the direction of elastic force.

In Trail 1, there was a mission instruction with a story setting before learning tasks: "in a virtual animal kingdom, a piglet has led a lazy life of eating and sleeping, and grows as plump as a little ball, even causing problems to move about. Its owner (the game player) needs to find a way using the knowledge of elastic force to help it move and gradually lose weight by passing through several game levels." The story setting aimed to stimulate learners' motivation through role-playing in a pleasant learning environment.

During the learning tasks, students would learn to identify the existence of elastic force. The tasks in Trial 1 consisted of 7 levels, with each scene of different levels related to the error-prone problems spotted in students' learning, transiting from simple to complex, general to specific. Take Level 5 as an example. Two scenes are shown in Figure 1 (a) for students to identify the existence of elastic force--the two small balls on the left touch each other but do not squeeze, while the two on the right touch and squeeze. Many students tended to mistakenly think that elastic force existed in both scenes. In the task shown in Figure 1 (b), students were allowed to move the barrier to different points and observed whether squeezing and elastic deformation occurred between the piglet and the balloon and whether it caused the piglet to roll. The demonstration of a balloon with obvious deformation was used to help students realize, through the task, that the conditions for generating an elastic force consist of both contact and elastic deformation. 


\section{Figure 1}

The game scene of Level 5

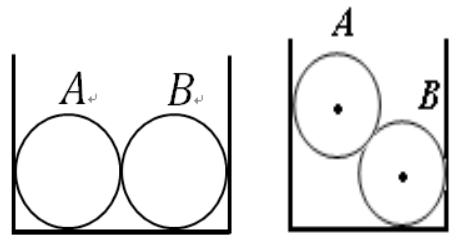

(a)

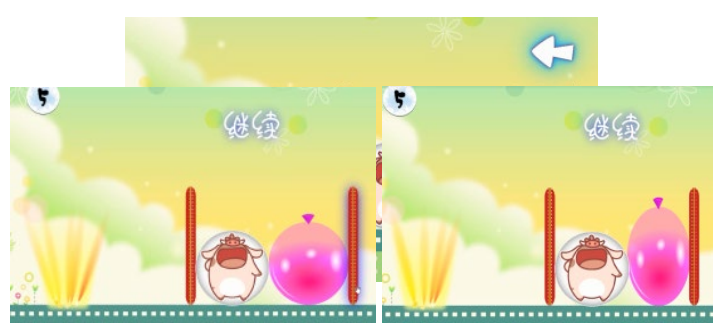

(b)

Notes:

(a) Two scenes for students to identify the existence of elastic force--the two small balls on the left touch each other but do not squeeze, while the two on the right touch and squeeze.

(b) After moving the barrier to different points, it can be observed whether elastic deformation occurs between the piglet and the balloon and whether it causes the piglet to roll.

In order to help students connect the learning tasks to specific scientific content knowledge, some test questions were provided immediately after the tasks with direct and immediate feedback. After the task in Level 5, for example, there were two questions: 1) "Is there always an elastic force between two bodies in contact?" Students were to choose "yes" or "no" to answer this question. 2) "What conditions are needed to generate an elastic force between objects?" Students were to choose "contact" or "contact and elastic deformation" to answer this question. The design of knowledge prompt was adopted here, and immediate feedback was given after students submitting the answer.

The setting of Trial 2 was similar to that of Trial 1. The story setting before learning tasks was that: "in a pleasant afternoon, the player controls the direction of a barrel by pressing the 'left' or 'right' arrow button, and launches the 'bullets' by pressing the 'space' button to hit the targets. If the player properly makes use of the direction of elastic force and succeeds making the 'bullet' return to the turntable, he will enjoy the afternoon with delicious snacks and cute animal friends." In the process of completing Trial 2, the player would learn that the direction of elastic force is opposite to the direction of deformation. In accordance with the error-prone situations noted in students' learning, the tasks included scenes of different types of contacts between two objects: plane-to-plane, plane-to-curve, curve-to-plane, curve-to-curve, point-to-plane and point-to-curve, falling into 6 levels. The task levels were designed to transit from simple to complex----first the plane-to-plane, and finally the point-to-curve. For example, the pictures in Figure 2 respectively describe the cases where the contact between the two objects was plane-to-plane (in Level 1), curve-to-curve (in Level 4) and point-to-curve (in Level 6).

\section{Figure 2}

Game scenes of level 1,4 and 6



(a)

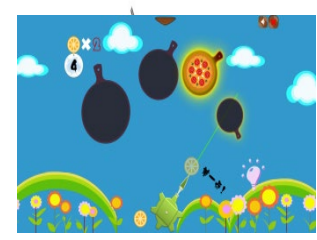

(b)

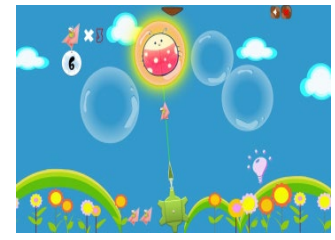

(c)

Notes:

(a) Plane-to-plane contact between the two objects;

(b)Curve-to-curve contact between two objects;

(c)Point-to-curve contact between two objects. 
As in Trial 1, to enhance students' understanding of the scientific content knowledge from the learning tasks, small quizzes were embedded after the tasks with direct and immediate feedback. For example, after the task in Level 4 with the contact of curve-to-curve between two objects, there was one question of small quiz (as shown in Figure 3): "when a football and a watermelon are put together in the bucket, which of the pictures correctly describes the direction of the elastic force of the watermelon against the football?" Here the design of application prompt was used, and feedback was given immediately after the answer submitted.

\section{Figure 3}

A question embedded after the task in Level 4

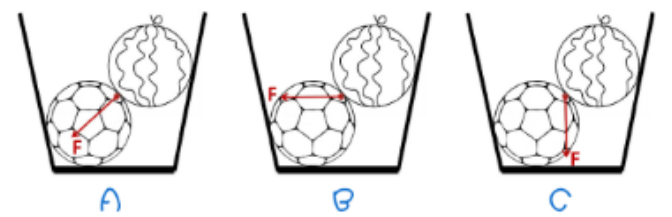

There were some special design of settings and guidelines in game-based learning tasks. In terms of interactive mode, mouse and keyboard was applied as the interactive media in the tasks, with mouse locating the position, the "left" and "right" arrow keys controlling the direction, and the "space" key determining the progress of the tasks. In terms of button setting, there was a "bulb" button in each level to provide assistance when needed, in addition to some buttons such as "exit", "volume", "menu", etc., which guaranteed the operation of the tasks. Some tool buttons such as "refresh" (replay), "brush", "screenshot", and "note" were provided, aiming to facilitate players' analyzing, recording and summarizing during the tasks, in order to better exert the educational function of game-based learning. As to feedback mechanism, there was relevant text, animation instructions and playful sound in each step to enrich the player's learning experience. At the end of each level, the accordant task evaluation was provided. Positive evaluation was represented by a sound of victory and the pass to the next level, while the negative evaluation was represented by a sound of failure and automatic replay.

\section{The Design of Educational Video on Learning Elastic Force}

Two video clips were designed as Lecture 1 and Lecture 2, respectively demonstrating the content knowledge of "identifying the existence of elastic force" in Trial 1 and "determining the direction of elastic force" in Trial 2. In Lecture 1, the instruction was provided including the introduction of trampoline competition in Olympic Games, the concept and types of elastic deformation, the demonstration of micro-deformation, the concept of elastic force and its application in daily life. The instruction in Lecture 2 started with introducing the vector property of force, which is helpful for learning the direction of elastic force. By introducing and analyzing trampoline, a typical case with obvious deformation, it led to the conclusion that "the direction of elastic force is opposite to the direction of deformation". The two video clips were made with Adobe Flash CS6 and Super screen recording software, aiming to allow students to carry out their autonomous learning with multimedia, instead of reading traditional paper materials.

\section{Worksheet}

Three learning strategies were employed in the present research: learning with printed materials (the traditional group), with educational video (the educational video group) and with game-based learning tasks (the game-based learning group). There was a worksheet prepared for both the traditional group and the educational video group. The questions in worksheets were extracted from the knowledge prompt questions in Trial 1 and the application prompt questions in Trial 2 in game-based learning. The design of worksheet was intended to make up for the inconsistency brought by the three different learning strategies.

\section{Assessment}

An assessment of 14 questions on elastic force was designed to evaluate students on how to identify the existence of elastic force and how to determine the direction of elastic force. Among those questions, Q1-Q6 were 
multiple choices, and Q7-Q14 allowed students to draw the direction of elastic force. While Q1-Q5 examined students' understanding on the existence of elastic force, Q6-Q14 about the understanding on the direction of elastic force. A sample question of multiple choices about conditions of elastic force is as follows (Figure 4):

\section{Figure 4}

A sample question of multiple choices about the existence of elastic force

In the figure, the horizontal ground $(\mathrm{OB})$ and the inclined plane $(\mathrm{OA})$ are frictionless, and the ball is in contact with both $\mathrm{OA}$ and $\mathrm{OB}$. Is there an elastic force at Point $a$ or Point $b$ ?
A. Both Point $a$ and Point $b$
B. Point $a$, not Point $b$
C. Point b, not Point a
D. Neither Point a nor Point b

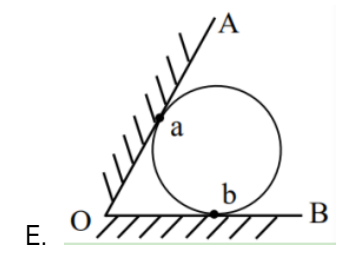

A sample question of drawing the direction of elastic force is shown below in Figure 5 :

\section{Figure 5}

A sample question of drawing the direction of elastic force In the figure, all the contact surfaces are assumed as frictionless. Please draw all elastic forces exerted
on the static bar $\mathrm{A}$.

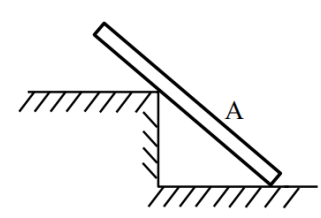

In order to research which types of guides enhanced students' game-based learning, 46 students were interviewed in the game-based learning group (the other 6 students in the group did not accept the interview) with the question of "what make you learn the scientific knowledge from game-based learning?"

\section{Participants and Procedure}

A total of 155 students in Year 10 from a secondary school in Guangzhou, China, were enrolled into the present research. Among the participants, there were 78 boys and 77 girls, with an average age of 16.0. The participants were from three parallel classes with a similar level of knowledge base. There were 52 students for each class and one student was absent because of sick leave. All students have not learned how to identify the existence of elastic force and how to determine the direction of elastic force in the school curriculum. All participants were randomly divided into three groups: the traditional group, the educational video group and the game-based learning group. In the traditional group, 52 students were applied with the physics textbook containing the related content of elastic force as the learning material, which was developed for secondary school students in Year 10 by the national textbook compilation team according to the national curriculum standard. In the educational video group, 51 students learned Lecture 1 and Lecture 2 through watching the pre-recorded video. Students in both the traditional group and the educational video group completed the worksheet after learning, and checked their responds using the reference answers attached to the worksheet. While 52 students in the game-based learning group learned through the game-based learning software and completed quizzes in the tasks. Figure 6 displays the scenes of three groups in learning. Each group was allowed 30 minutes to accomplish the learning tasks. Then, students in the game-based learning group were arranged to attain the interviews, by four research assistants, after finishing the learning tasks. A week later, all the three groups were simultaneously given a 30-minute test with 14 questions on elastic force. 


\section{Figure 6}

The scene of three groups of students in learning elastic force

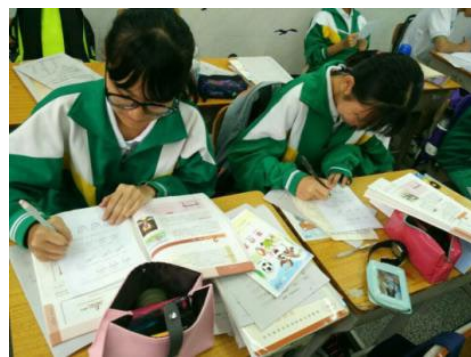

(a)the traditional group

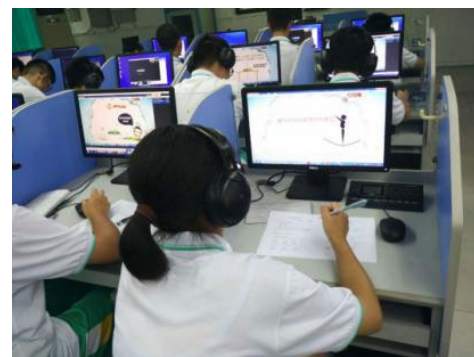

(b)the educational video group

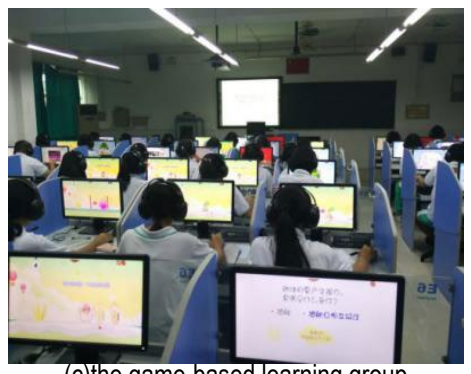

(c)the game-based learning group

Data Analysis

When grading the questions in the assessment, two different principles were adopted for multiple-choice questions and questions of drawing the elastic force. For multiple-choice questions, 1 score was assigned for each correct answer while a wrong answer awarded no score. For questions of drawing the elastic force, scores of 2, 1 or 0 were given depending on the correctness and completeness of drawing the elastic force. Specifically, 2 scores were for drawing complete elastic forces with correct direction, 1 score for drawing either incomplete elastic forces or incorrect directions, and 0 for drawing neither complete elastic forces nor with the correct directions. Q1-Q5 took up 5 scores out of the total 22, examining students' understanding of the existence of elastic force, while Q6-Q14 took up 17 scores, testing their understanding on the direction of elastic force.

When analyzing the interview data, it was necessary to calculate the number of prompts of different types in game-based learning that was mentioned by students as helpful for them in learning the content knowledge of elastic force. One student may have referred to more than one type of prompts. The proportion of each type of prompts mentioned was compared and ranked, in order to find out the most effective prompt in students'learning.

\section{Research Results}

\section{Effect of Different Methods on Student Learning Achievement}

In order to examine whether there were differences on students' overall achievement in learning elastic force among the three groups: the traditional group, the educational video group and the game-based learning group, an analysis of variance (ANOVA) was performed. Three groups were used as an independent variable, while student performances on the elastic force assessment were used as the dependent variable. The Levene's test was conducted to test homogeneity of variance and the result showed that there was no significant difference in variance among the groups $(p=.53)$. As seen in Table 1, the ANOVA result illustrates that there was a significant difference on student performances on elastic force assessment with a medium effect size for eta-squared $(F(2,152)$ $\left.=8.01, p<.001, \eta^{2}=.10\right)$. To further research how teaching methods of the three groups influenced students' overall performance on the elastic force assessment, Post-hoc comparisons were conducted. From the Post-hoc results, the differences have been detected statistically significantly between the game-based learning group and the educational video group, and also between the game-based learning group and the traditional group. Students in the game-based learning group achieved a noticeably higher performance on elastic force assessment $(M=16.48$, $S D=3.24)$ than those in the educational video group $(M=14.86, S D=4.22 ; p=.03)$ and those in the traditional group $(M=13.58, S D=3.60 ; p<.001)$. However, there was no statistically significant difference between the educational video group and the traditional group $(p=.08)$.

The elastic force assessment was to test students' learning achievement of the conceptual understanding about the existence of elastic forces, as well as determining the direction of the elastic force. To evaluate the effect of three teaching methods (the traditional group, the educational video group and the game-based learning group) on the two aspects, a one-way MANOVA was performed. Three different groups of teaching methods were used as an independent variable, and student performances of identifying the existence of elastic force and determining the direction of elastic force were used as two dependent variables. The Levene's tests of variance homogeneity were both met among the groups ( $p=.49$ for the existence identifying and $p=.46$ for the direction determining). As 
seen in Table 1, the MANOVA result conforms the previous result that there was significant difference on student performances on elastic force assessment (Wilk's Lambda $=.87,(F(4,152)=5.52, p<.001)$. Follow-up ANOVAs were employed to identify which aspect yield significant differences among the teaching methods. Both the existence identifying $\left(F(2,152)=6.40, p<.01, \eta^{2}=.08\right)$ and direction determining $\left(F(2,152)=6.53, p<.01, \eta^{2}=.08\right)$ contribute to the significant multivariate effects with medium effect sizes.

\section{Table 1}

An ANOVA result of student learning achievements among the three groups: the traditional group, the educational video group and the game-based learning group

\begin{tabular}{|c|c|c|c|c|c|c|c|c|c|}
\hline & Groups & $N$ & $M(S D)$ & Value & $F$ & $d f$ & Error $d f$ & $p$ & $\begin{array}{l}\text { Post hoc } \\
\text { (LSD) }\end{array}$ \\
\hline \multirow{3}{*}{$\begin{array}{l}\text { Overall perfor- } \\
\text { mances }\end{array}$} & Traditional & 52 & $13.58(3.60)$ & & \multirow{3}{*}{$8.01^{* \star *}$} & \multirow{3}{*}{2} & & \multirow{3}{*}{.001} & \multirow{3}{*}{$\begin{array}{c}\text { Game-based learning } \\
>\text { Educational video }(p=.03) \\
\text { Game-based learning } \\
>\text { Traditional }(p<.001)\end{array}$} \\
\hline & $\begin{array}{c}\text { Educational } \\
\text { video }\end{array}$ & 51 & $14.86(4.22)$ & & & & & & \\
\hline & $\begin{array}{l}\text { Game-based } \\
\text { learning }\end{array}$ & 52 & $16.48(3.24)$ & & & & & & \\
\hline \multirow{3}{*}{$\begin{array}{l}\text { Existence of } \\
\text { elastic force }\end{array}$} & Traditional & 52 & $3.73(1.01)$ & & \multirow{3}{*}{$6.40^{\star *}$} & \multirow{3}{*}{2} & & \multirow{3}{*}{.002} & \multirow{3}{*}{$\begin{array}{c}\text { Game-based learning } \\
>\text { Educational video }(p=.005) \\
\text { Game-based learning } \\
>\text { Traditional }(p=.001)\end{array}$} \\
\hline & $\begin{array}{l}\text { Educational } \\
\text { video }\end{array}$ & 51 & $3.65(.87)$ & & & & & & \\
\hline & $\begin{array}{l}\text { Game-based } \\
\text { learning }\end{array}$ & 52 & $4.27(.99)$ & & & & & & \\
\hline \multirow{3}{*}{$\begin{array}{l}\text { Direction of } \\
\text { elastic force }\end{array}$} & Traditional & 52 & $9.85(3.26)$ & & \multirow{3}{*}{$6.53^{\star *}$} & \multirow{3}{*}{2} & & \multirow{3}{*}{.002} & \multirow{3}{*}{$\begin{array}{c}\text { Game-based learning > } \\
\text { Traditional }(p=.001) \\
\text { Educational video > } \\
\text { Traditional }(p=.04)\end{array}$} \\
\hline & $\begin{array}{l}\text { Educational } \\
\text { video }\end{array}$ & 51 & $11.22(3.92)$ & & & & & & \\
\hline & $\begin{array}{l}\text { Game-based } \\
\text { learning }\end{array}$ & 52 & $12.21(2.80)$ & & & & & & \\
\hline Wilk's lambda & & & & .87 & 5.52 & 4 & 302 & .001 & \\
\hline
\end{tabular}

Post-hoc comparisons were applied for further analysis on influence of three different teaching methods on student performances in both the existence identifying aspect and the direction determining aspect. It can be seen that the game-based learning group performed significantly better on identifying the existence of elastic force $(M=4.27, S D=.99)$ than the educational video group $(M=3.65, S D=.87 ; p=.005)$, and the traditional group $(M=3.73, S D=1.01 ; p=.001)$. But no statistically significant difference was detected between the educational video group and the traditional group $(p=.66)$. It can also be seen that the game-based learning group achieved much better performances on determining the direction of elastic force than the traditional group ( $p=.001)$. It was also noted that the educational video group reported higher level of problem-solving skills than the traditional group $(p=.04)$, whereas there was no significant difference between the game-based learning group and the educational video group $(p=.13)$ in this aspect.

\section{Student Opinions on What Make Them Learn from Game-based Learning}

After the learning tasks, 46 students in the game-based learning group accepted the interview and expressed their opinions on the question "what make you learn the scientific knowledge from game-based learning?" The question was designed to find out which types of guides, from students' point of view, enhanced students' gamebased learning. 


\section{Figure 7}

Percentage of students' responses on the types of guides that enhance their learning

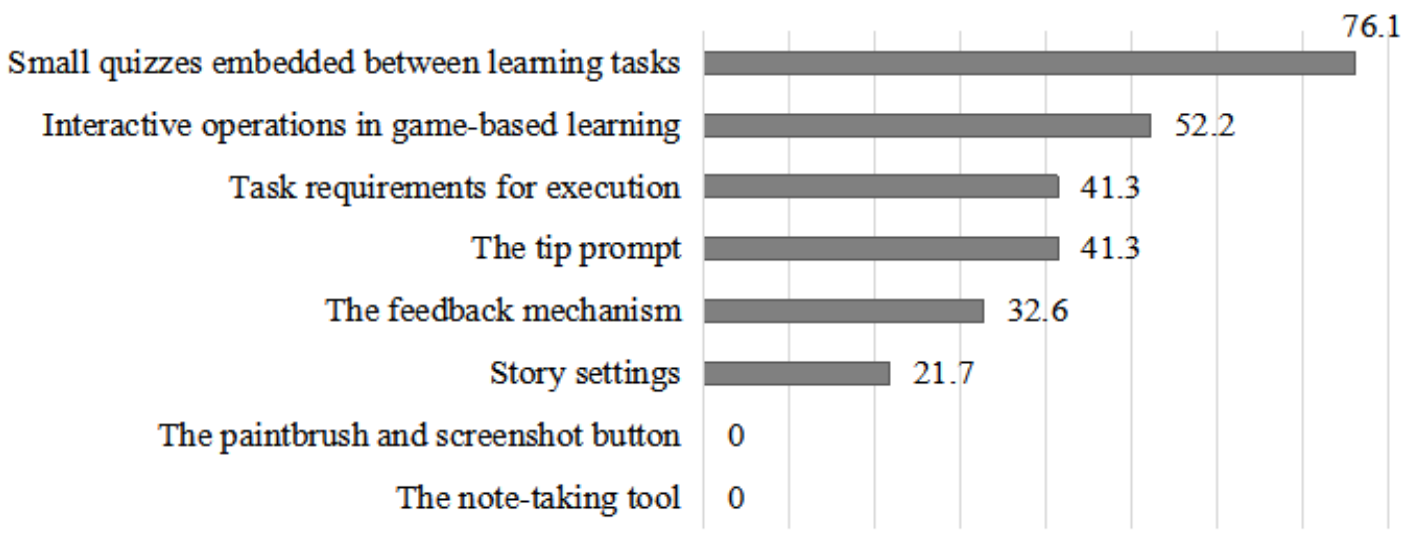

As seen in Figure 7, among 46 interviewees, 76.1\% found the small quizzes embedded between learning tasks most effective in helping them dig the knowledge in game-based learning. In the design of game-based learning, some small questions were set as knowledge prompt immediately after the game tasks in Trial 1 and other small quizzes as application prompt in Trial 2, with the purpose to enhance students' understanding of the scientific content knowledge from the learning tasks. This design received positive feedback from the students, accounting for the largest percentage. Following that, $52.2 \%$ of students thought that interactive operations in the learning tasks were of great help to master the content knowledge of elastic force. In the present research, the interactive mode was mainly the combination of mouse and keyboard, which was acknowledged by most students from the result. Then, students claimed that the task requirements for operation and the tip prompt had a positive effect on their knowledge learning in the game, accounting for $41.3 \%$. In addition, $32.6 \%$ of the interviewees mentioned that the feedback mechanism of game-based learning (including animation feedback and sound feedback) also promoted their knowledge acquisition. There were two types of feedback in the design of game-based learning. One is the instant feedback given to students in the process of performing tasks. The other was provided immediately after students submitting answers to those small quizzes between learning tasks. Furthermore, a few interviewees (21.7\%) claimed that the story settings effectively inspired them with clear learning goal.

\section{Discussion}

\section{Discussion on the Effect of Different Methods on Student Learning Achievement}

The results of this research confirm that game-based learning has a significantly positive effect on students' conceptual learning. Game-based learning in the present research aimed at teaching students to identify the existence of elastic force and determine the direction of elastic force. In respect of identifying the existence of elastic force, the game-based learning group not only reached a significantly higher achievement than the traditional group, but also performed meaningfully better than the educational video group. In terms of determining the direction of elastic force, the game-based learning group also had more excellent performance than the traditional group, while the educational video group did better than the traditional group. In a word, the game-based learning group performed the best among the three groups, followed by the educational video group, while the traditional group showed the lowest level of knowledge acquisition. As reflected by teachers in the interview, it is difficult for students to perceive the existence of elastic force and the direction of elastic force. There is an opportunity, in the present research, for students to experience the difficult concept in a game-based learning environment, which provides more intuitive and perceivable demonstration and more visual operation. The results support the perspective of the previous research that game-based learning is an effective method in enhancing students' abstract concepts (Raybourn \& Bos, 2005; Cheng et al., 2015; Mayo, 2007; Quintana et al., 2004). 
According to the research results, the educational video group outperformed the traditional group to some extent, with its apparent strength laying in determining the direction of elastic force but not extending to identifying the existence of elastic force. Students' abilities to identify the existence of elastic force in the educational video group are far behind those in the game-based learning group. As mentioned in the literature review, multimedia learning environments, which are designed with multiple resources, demonstrate their significance in improving student understanding and learning performance (Mayer, 2003). Both educational video method and game-based learning were media-rich instructions with multiple resources, such as texts, graphs, pictures, and animations, but their effectiveness does not reach up to the same level. To explain the different levels of effectiveness between the game-based learning group and the educational video group, it is hypothesized that game-based learning has more interactive features compared with educational video. As most students (52.5\%) in the interview voted that interactive operations in game-based learning were of great help for them to master the concept of elastic force. The interactive features of game-based leaning allow students to visually observe and to simulatively experience how their operations fail or succeed in the completion of learning tasks. Educational video without interactive experience, which is limited to pre-recorded video clip of game play, tends to facilitate text comprehension, but inadequate in promoting complicated conceptual understanding (Gros, 2007; Ritterfeld et al., 2009). Game-based learning, on the other hand, enabled students to have a sense of presence that allows them to immerse in the observation and exploration in a virtual environment (Faiola et al., 2013; Schrader \& Bastiaens, 2012). Especially, game-based learning is highly valued with the features such as interactivity between tasks and players, realistic visualization of the actions and real-time feedback (Zhou et al., 2011; Sitzmann, 2011; Faiola et al., 2013; Schrader \& Bastiaens, 2012). In addition, learning interest and motivation could be generated through game-based learning, which helps center students' attention and maintain longer concentration (Garris et al., 2002; Huang et al., 2015; Papastergiou, 2009).

\section{Discussion on the Effect of Guidelines in Game Design}

The design of guidelines embedded in game-based learning is considered as an important instructional strategy to help learners advance their learning abilities (Palinscar \& Brown, 1984). In particular, guidelines could accelerate students to reflect on the related knowledge and prompt them to apply the knowledge to the tasks (e.g., Tsai et al., 2013). However, guidelines with different levels of guidance designed for game-based learning may bring different effects on student learning achievement (e.g., Kirschner et al., 2006; Chang, 2016). In this research, guides were provided in the design of game-based learning with direct and immediate feedback. Knowledge prompt was designed in Trial 1 when identifying the existence of elastic force, and application prompt was designed in Trial 2 when determining the direction of elastic force. It is assumed that the integration of knowledge prompt and application prompt in the design with direct and immediate feedback would improve student learning outcomes. There were no direct instructions on content knowledge embedded in the procedures. Besides, no preview materials or instructions were provided to prompt students with the associated content knowledge before learning tasks. The result demonstrated that students in the game-based learning group did show the highest level of knowledge acquisition among the three groups. Hence, there were $76.1 \%$ of the interviewees who supported that prompts embedded between learning tasks effectively bridged the gap between the game environment and the knowledge structures. Reviewing the previous research literature, there were some voices that did not support minimal guidance in game-based learning, but direct instructional guidance on the procedures (e.g., Kirschner et al., 2006), strongly guided instruction (Moreno, 2004), specific guidance to assist the cognitive processing essential for learning (Kirschner et al., 2006). Although guides with direct or strong guidance could reduce students' cognitive load, it lacks the process for students to explore the unknown. The research was to adhere to the point of view of constructive learning and exposed students to game-based learning with minimally guided instruction (Adams et al., 2009). As seen in the present research, without direct and strong guidance, students were capable of accomplishing knowledge acquisition efficiently. Minimal guidance may be beneficial to students' cognitive engagement (Chang, 2016). As it is claimed that successful game-based learning should allow students to explore the unknown world at their own pace and satisfy their needs to be an explorer (Rapp, 2015).

Except for the interactive characteristic of game-based learning and guidelines embedded in the tasks, it could be seen from the interview that many students voted for some other features of the design, including task requirements for execution (41.3\%), the tip prompt function (41.3\%), the feedback mechanism (32.6\%) and the story settings (21.7\%). It indicates that different types of guides may be required to support students to better accomplish the learning tasks. In terms of the task requirements, there is a mission with a story setting for both 
learning modules, to stimulate learners' motivation through role-playing in a pleasant learning environment. The game-based learning consisted of 7 levels in Trial 1 and 6 levels in Trial 2, transiting from simple to complex, general to specific, accordant with students' cognitive development from easy to difficult, from the superficial to the higher-order. Students' understanding the goal and the requirements of the tasks before starting the operation helps stimulate their learning motivation and challenge the difficulties. So, students would do the task consciously and think about the strategies to achieve the completion of the task. In game-based learning, clear expression and reflection on the target content knowledge should also be carefully designed to achieve teaching purposes (e.g., van der Meij et al., 2011).

In aspect of tip prompt function, students' responses indicated that when they encountered difficulties and were unable to continue the game tasks, they could benefit from the tip prompt function and successfully proceed and achieve the game goals. Because students learn without the direct intervention or guidance of teachers in game-based learning, they would have suffered great trouble and frustration if there is no tip prompt function. The guide of tip prompt could help students build their confidence and provide necessary support for solving the difficulties in game-based learning. With the tip prompt function, it is possible to train students to decide whether or not to use the guide of tip prompt to solve difficulties. It is an opportunity for them to strike a balance between using the tip prompt and dealing with setbacks on their own (Bjork \& Bjork, 2011). From another perspective, instant feedback was considered by interviewees as an effective bridge built between learning tasks and knowledge acquisition. It has been pointed out that feedback is one of the key factors to consider in designing engaging experience (Prensky, 2001). As with tip prompt, instant feedback could reduce students' frustration with the task operation, preventing them from delusions of understanding (e.g., Hsu \& Tsai, 2013). Positive correlation has been found between giving feedback immediately and obtaining learning achievement in game-based learning environments (e.g., Lee et al., 2010). Real-time feedback encourages students to understand knowledge in game-based learning and provides clear guides on how to better apply content knowledge to the task.

However, no students in the interview mentioned that the paintbrush and screenshot button in the design of game-based learning was helpful, and none of the students thought that the note-taking tool in the design was beneficial to their knowledge acquisition in the game-based environment. It can be seen that, game-based learning requires the customization of appropriate guides to improve the learning effectiveness. Appropriate guides would be an effective help for students to acquire knowledge in game-based learning (Jabbar \& Felicia, 2015). As Becker suggested, it is necessary to incorporate a student's perspective and applicable guidance into the design process for providing engaging learning experience (Becker, 2007). Hence, complementing gamebased learning with well-designed guides could help refine learners' strategies and enhance their learning outcomes (Fisch, 2005). With inappropriate guides, the effectiveness of learning in game-based learning would be greatly limited.

\section{Conclusions and Implications}

In this research, game-based learning tasks were designed in the physics domain with guides providing direct and immediate feedback. A pilot interview was conducted in advance with 64 physics teachers to better understand the problems of general teaching practice in the physics domain and to provide authentic and reliable reference for the design of game-based learning. The first research question was to research whether students could better acquire conceptual knowledge with guides in the game-based learning group. The research was conducted among three different groups: the traditional group, the educational video group, and the gamebased learning group. The result showed that the game-based learning group performed the best among the three groups, followed by the educational video group, and the traditional group showed the lowest level of knowledge acquisition. It confirms our assumption and supported the perspective of the previous research that game-based learning is an effective method in enhancing students' abstract concepts understanding.

The second research question aimed at finding out which types of guides facilitated students' game-based learning from students' perspective. 46 students were interviewed and stated their opinions. From the interview, knowledge prompt and application prompt in design were reported as helpful by most students. The interactive characteristic of game-based learning was admittedly considered useful for students' knowledge acquisition. Besides, students also claimed that they benefited from other features of the design, including task requirements for execution, the tip prompt function, the feedback mechanism, and the story settings. However, no students in the interview mentioned that the paintbrush, screenshot button and the note-taking tool in the design were helpful to their game-based learning. Therefore, to incorporate students' perspective and applicable guidance 
into the design is necessary for providing engaging learning experience. It requires the customization of appropriate guides to improve the effectiveness of game-based learning.

Despite the encouraging results with significantly different effect among the traditional group, the educational video group and the game-based learning group in the present research, limitations exist in the research design. On the one hand, this research only compared the effect between game-based learning with guides and traditional teaching method. It could not provide evidence to identify the effect between game-based learning with minimal guidance and that with direct or strong guidance. On the other hand, the present research explored the kind of guides that enhanced student learning in game-based learning only from students' subjective consciousness, rather than from their game-based learning effect. Moreover, the interview was only conducted among students in the game-based learning group, therefore, it was not clear how students perceive the difference between game-based learning and the traditional teaching method. Future work should carry out the comparison with different levels of guided instruction to explore whether minimal guidance works better than direct or strong guidance, or the two work equally well. It will also be meaningful to examine the learning effects of different types of guides embedded in game with minimally guided instruction. Finally, more efforts may involve conducting a switch research to inquire into the different effects and perception between game-based learning with minimal guidance and the traditional teaching method from the perspective of the same learner.

\section{Acknowledgements}

The authors would like to acknowledge the help of the anonymous reviewers. The research is supported in part by 2020 Guangzhou Philosophy and Social Science Planning Fund of P.R. China under the Grant No. 2020GZQN20.

\section{References}

Adams, W. K., Paulson, A., \& Wieman, C. E. (2009). What levels of guidance promote engaged exploration with interactive simulations? In H. Charles, S. Mel, \& H. Leon (Eds.), 2008 physics education research conference. AlP conference proceedings (Vol. 1064, pp. 59-62). AIP Press.

Barzilai, S., \& Blau, I. (2014). Scaffolding game-based learning: Impact on learning achievements, perceived learning, and game experiences. Computers \& Education, 70, 65-79. http://dx.doi.org/10.1016/j.compedu.2013.08.003

Becker, K. (2007). Pedagogy in commercial video games. In D. Gibson, A. Clark, \& M. Prensky (Eds.), Games and simulations in online learning: Research and development frameworks. Information Science Publishing.

Bjork, E. L., \& Bjork, R. A. (2011). Making things hard on yourself, but in a good way: Creating desirable diffificulties to enhance learning. In M. A. Gernsbacher, R. W. Pew, L. M. Hough, \& J. R. Pomerantz (Eds.), Psychology and the real world: Essays illustrating fundamental contributions to society (pp. 56-64). Worth Publishers.

Bruner, J. (1985). Vygotsky: A historical and conceptual perspective. In I.V. Wertsch (Eds.), Culture, communication and cognition: Vygotskian perspectives (pp. 21-34). Cambridge University Press.

Chang, C. C., Liang, C., Chou, P. N., \& Lin, G. Y. (2017). Is game-based learning better in flow experience and various types of cognitive load than non-game-based learning? perspective from multimedia and media richness. Computers in Human Behavior, 71, 218-227.

Chang, H. Y. (2016). How to augment the learning impact of computer simulations? The designs and effects of interactivity and scaffolding. Interactive Learning Environments, 25(8), 1083-1097. https://doi.org/10.1080/10494820.2016.1250222

Charsky, D., \& Ressler, W. (2011). "Games are made for fun": Lessons on the effects of concept maps in the classroom use of computer games. Computers \& Education, 56(3), 604-615. http://dx.doi.org/10.1016/j.compedu.2010.10.001

Chen, C. H., Wang, K. C., \& Lin, Y. H. (2015). The comparison of solitary and collaborative modes of game-based learning on students' science learning and motivation. Educational Technology \& Society, 18(2), 237-248.

Cheng, M. T., She, H. C., \& Annetta, L. A. (2015). Game immersion experience: Its hierarchical structure and impact on game-based science learning. Journal of Computer Assisted Learning, 31(3), 232-253.

Davis, E. A., \& Linn, M. C. (2000). Scaffolding students' knowledge integration: Prompts for reflection in KIE. International Journal of Science Education, 22(8), 819-837. http://dx.doi.org/10.1080/095006900412293

D'Angelo, C. (2010). Scaffolding vector representations for student learning inside a physics game. Unpublished doctoral dissertation. Arizona State University.

Faiola, A., Newlon, C., Pfaff, M., \& Smyslova, O. (2013). Correlating the effects of flow and telepresence in virtual worlds: Enhancing our understanding of user behavior in game-based learning. Computers in Human Behavior, 29(3), 1113-1121.

Fisch, S. M. (2005). Making educational computer games "educational". In Proceedings of the 2005 conference on Interaction design and children (pp. 56-61). ACM Press.

Garris, R., Ahlers, R., \& Driskell, J. (2002). Games, motivation, and learning: A research and practice model. Simulation \& Gaming, 33(4), 441-467.

Gros, B. (2007). Digital games in education: The design of games-based learning environments. Journal of Research on Technology in Education, 40(1), 23-38. 
Hmelo-Silver, C. E., Duncan, R. G., \& Chinn, C. A. (2007). Scaffolding and achievement in problem-based and inquiry learning: A response to Kirschner, Sweller, \& Clark (2006). Educational Psychologist, 42(2), 99-107.

Hsu, C. Y., \& Tsai, C. C. (2013). Examining the effects of combining self-explanation principles with an educational game on learning science concepts. Interactive Learning Environments, 21(2), 104-115.

Huang, Y. M., Huang, S. H., \& Wu, T. T. (2015). Embedding diagnostic mechanisms in a digital game for learning mathematics. Education Technology Research and Development, 62(2), 187-207.

Jabbar, A. I. A., \& Felicia, P. (2015). Gameplay engagement and learning in game-based learning: A systematic review. Review of Educational Research, 85(4), 740-779. http://dx.doi.org/10.3102/0034654315577210

Kauffman, D., Ge, X., Xie, K., \& Chen, C.-H. (2008). Prompting in web-based environments: Supporting self-monitoring and problem-solving skills in college students. Journal of Educational Computing Research, 38(2), 115-137. http://dx.doi. org/10.2190/EC.38.2.a

Kirschner, P. A., Sweller, J., \& Clark, R. E. (2006). Why minimal guidance during instruction does not work: An analysis of the failure of constructivist, discovery, problem-based, experiential, and inquiry-based teaching. Educational Psychologist, 41(2), 75-86.

Lai, J. Y., \& Chang, C. Y. (2011). User attitudes toward dedicated e-book readers for reading: The effects of convenience, compatibility and media richness. Online Information Review, 35(4), 558-580.

Lee, C.-Y., \& Chen, M.-P. (2009). A computer game as a context for non-routine mathematical problem solving: The effects of type of question prompt and level of prior knowledge. Computers \& Education, 52(3), 530-542. http://dx.doi.org/10.1016/j. compedu.2008.10.008

Lee, H., Lim, K., \& Grabowski, B. (2010). Improving self-regulation, learning strategy use, and achievement with metacognitive feedback. Educational Technology Research \& Development, 58(6), 629-648. http://dx.doi.org/10.1007/s11423-010-9153-6

Liu, H. S., Liao, H. L., \& Pratt, J. A. (2009). Impact of media richness and flow on e-learning technology acceptance. Computers \& Education, 52(3), 599-607.

Mayer, R. E. (2003). The promise of multimedia learning: Using the same instructional design methods across different media. Learning and Instruction, 13(2), 125-139.

Mayer, R. E., \& Moreno, R. (2003). Nine ways to reduce cognitive load in multimedia learning. Educational Psychology, 38(1), 43-52.

Mayo, M. J. (2007). Games for science and engineering education. Communications of the ACM, 50(7), 30-35.

Moreno, R. (2004). Decreasing cognitive load in novice students: Effects of explanatory versus corrective feedback in discoverybased multimedia. Instructional Science, 32, 99-113.

Palinscar, A., \& Brown, A. (1984). Reciprocal teaching of comprehension-fostering and comprehension-monitoring activities. Cognition and Instruction, 1, 117-175.

Papastergiou, M. (2009). Digital game-based learning in high school computer science education: Impact on educational effectiveness and student motivation. Computers \& Education, 52(1), 1-12.

Prensky, M. (2001). Digital game-based learning. McGraw-Hill.

Quintana, C., Reiser, B. J., Davis, E. A., Krajcik, J., Fretz, E., Duncan, R. G., \& Soloway, E. (2004). A scaffolding design framework for software to support science inquiry. Journal of the Learning Sciences, 13(3), 337-386.

Rapp, A. (2015). Designing interactive systems through a game lens: An ethnographic approach. Computers in Human Behavior, $71,455-468$

Raybourn, E. M., \& Bos, N. (2005). Design and evaluation challenges of serious games. Paper presented at the CHI'05 extended abstracts on human factors in computing systems.

Ritterfeld, U., Shen, C., Wang, H., Nocera, L., \& Wong, W. L. (2009). Multimodality and interactivity: Connecting properties of serious games with educational outcomes. CyberPsychology and Behavior, 12(6), 691-697.

Schrader, C., \& Bastiaens, T. J. (2012). The influence of virtual presence: Effects on experienced cognitive load and learning outcomes in educational computer games. Computers in Human Behavior, 28(2), 648-658.

Shepherd, M. M., \& Martz, W. B. (2006). Media richness theory and the distance education environment. The Journal of Computer Information Systems, 47, 114-122.

Sitzmann, T. (2011). A meta-analytic examination of the instruction effectiveness of computer-based simulation games. Personnel Psychology, 64, 489-528.

Steffe, L. P., \& Gale, J. E. (1995). Constructivism in education. Lawrence Erlbaum.

Sun, P. C., \& Cheng, H. K. (2007). The design of instructional multimedia in e-learning: A media richness theory-based approach. Computers \& Education, 49(3), 662-676.

Tsai, F.-H., Kinzer, C., Hung, K.-H., Chen, C.-L., \& Hsu, I.-Y. (2013). The importance and use of targeted content knowledge with scaffolding aid in educational simulation games. Interactive Learning Environments, 21(2), 116-128.

Tüzün, H., Yilmaz-Soylu, M., Karakus, T., Inal, Y., \& Kızılkaya, G. (2009). The effects of computer games on primary school students' achievement and motivation in geography learning. Computers \& Education, 52(1), 68-77.

van den Boom, G., Paas, F., van Merrienboer, J. J. G., \& van Gog, T. (2004). Reflection prompts and tutor feedback in a web-based learning environment: Effects on students' self-regulated learning competence. Computers in Human Behavior, 20(4), 551-567.

van der Meij, H., Albers, E., \& Leemkuil, H. (2011). Learning from games: Does collaboration help? British Journal of Educational Technology, 42(4), 655-664. http://dx.doi.org/10.1111/j.1467-8535.2010.01067.x

Wu, W. H., Chiou, W. B., Kao, H. Y., Hu, C. H. A., \& Huang, S. H. (2012). Re-exploring game-assisted learning research:The perspective of learning theoretical bases. Computers \& Education, 59(4), 1153-1161. http://dx.doi.org/10.1016/j.compedu.2012.05.003 
Young, M. F., Slota, S., Cutter, A. B., Jalette, G., Mullin, G., Lai, B., ...Yukhymenko, M. (2012). Our princess is in another castle: A review of trends in serious gaming for education. Review of Educational Research, 82(1), 61-89. http://dx.doi. org/10.3102/0034654312436980

Zhou, S., Han, J., Pelz, N., Wang, X., Peng, L., \& Xiao, H., et al. (2011). Inquiry style interactive virtual experiments: A case on circular motion. European Journal of Physics, 32(6), 1597-1606.

Hui Zeng

Shao-Na Zhou

(Corresponding author)

Gui-Rong Hong

Qiu-Ye Li

Shao-Qiu Xu
Ph.D., School of Physics and Telecommunication Engineering, South China Normal University, Guangzhou 510006, China.

E-mail: zenghui011222@163.com

Associate Professor, School of Physics and Telecommunication Engineering, South China Normal University, Guangzhou 510006, China.

E-mail:zhou.shaona@m.scnu.edu.cn

Teacher, Shenzhen Senior High School Group, Shenzhen, 518118, China

E-mail: 491110232@qq.com

M.S., School of Physics and Telecommunication Engineering, South China Normal University, Guangzhou 510006, China.

E-mail: 2019021855@m.scnu.edu.cn

Associate Professor, Faculty of Information Engineering, Guangdong University of Technology, Guangzhou 510006, China. E-mail: shaoqiuxu@gdut.edu.cn 